\title{
Determinants of Modern Family Planning Methods in the Oromia, Amhara, and Somali Regions, Ethiopia: A Community-Based, Cross-Sectional Mixed Methods Study
}

Hocheol Lee

Yonsei University College of Health Sciences

Eshetu Girma Kindane

Addis Ababa University School of Public Health

Young Ah Doh

Korea International Cooperation Agency

Eun Woo Nam ( $\square$ ewnam@yonsei.ac.kr)

Yonsei University https://orcid.org/0000-0001-6584-0658

\section{Research}

Keywords: family planning methods, Ethiopia, reproductive health, population control, birth-control

Posted Date: September 3rd, 2020

DOI: https://doi.org/10.21203/rs.3.rs-66142/v1

License: (c) (i) This work is licensed under a Creative Commons Attribution 4.0 International License. Read Full License 


\section{Abstract}

Background: In 2019, Ethiopia had a total fertility rate of 4.2 births per woman with the rates varying significantly across regions. The Federal Ministry of Health of Ethiopia announced "Ethiopia FP 2020" to address the high fertility rate, aiming to reduce it to 3.0 by 2020 . This study aimed to identify the determinants of the use of modern family planning services in the Amhara, Oromia, and Somali regions.

Methods: A community-based, cross-sectional mixed methods study was conducted, using quantitative and qualitative data. The quantitative data were subjected to binary logistic regression analyses. Participants included over 4,117 married men and women aged 15-65 years old.

Results: Respondents in Oromia were 8.673 times more likely to have modern family planning methods than those in Somali. Participants in Amhara were 5.183 times more likely to have modern family planning methods than their Somali counterparts. Women, married respondents, and recipients of media messages were more likely to have family planning experience. Family planning discussions with Health Extension Workers and health professionals played a significant role in modern family planning.

Conclusion: Establishing a family planning strategy that considers the sociocultural characteristics of each region might help address regional contexts. Everyone in Somali-especially husbands and religious leaders-must be educated in family planning and funds be made available to deploy advanced measures for the same.

\section{Plain English Summary}

In 2019, Ethiopia had a total fertility rate of 4.2 births per woman with the rates varying significantly across regions. The Federal Ministry of Health of Ethiopia announced "Ethiopia FP 2020" to address the high fertility rate, aiming to reduce it to 3.0 by 2020 . This study aims to identify the determinants of the use of modern family planning methods in three regions of Ethiopia. We selected the three largest from the nine regions in Ethiopia, being the Amhara, Oromia, and Somali regions. The target group was married women and men living with a partner such as a husband, wife, or cohabitee in Amhara, Oromia, and Somali regions in Ethiopia. Participants included over 4,117 married men and women aged 15-65 years old. Respondents in Oromia were 8.673 times more likely to have modern family planning methods than those in Somali. Participants in Amhara were 5.183 times more likely to have modern family planning methods than their Somali counterparts. Family planning discussions with Health Extension Workers and health professionals played a significant role in modern family planning. Establishing a family planning strategy that considers the sociocultural characteristics of each region might help address regional contexts. Everyone in Somali-especially husbands and religious leaders-must be educated in family planning and funds be made available to deploy advanced measures for the same.

\section{Background}

The world's population has grown by 80 million people every year since 2000, exceeding 7.7 billion in 2019 [1]. Global population growth is expected to be concentrated in sub-Saharan Africa, which is home to the world's poorest countries, making population control in the region important. In particular, among the 20 countries with the highest population growth rates, 19 of them are located in sub-Saharan Africa [1]. The total fertility rate in developed countries, as defined by the Organization for Economic Co-operation and Development (OECD), has decreased to 1.7, while in sub-Saharan Africa it has increased to 4.6 [1].

In 2017, to address the growing population problems in developing countries, the UK Department for International Development, the Bill \& Melinda Gates Foundation, and United Nations Population Fund (UNFPA) invited recipient 
countries, international organizations, civilian groups, private organizations, and research institutes that were conducting family planning projects to hold an international conference and set common goals for worldwide population control $[2,3]$. In particular, they decided to support the right of an additional 120 million women of childbearing age in developing countries, including sub-Saharan Africa, to decide for themselves whether, when, and how many children to have. It was predicted that this would potentially prevent 100 million unwanted pregnancies, 50 million abortions, and 3 million maternal and child deaths [2]. According to the UNFPA report, family planning can reduce the total fertility rate and improve the health levels of mothers and newborns. In addition, it is expected to improve the economic levels of families by increasing opportunities for women's social/economic activities and in turn, lead to the economic development of countries [4].

In 2019, Ethiopia as the 12th most populous country in the world, had a total fertility rate of 4.2 . It is expected to be the 8th most populous country in the world and 5th among developing countries by 2050 [1]. However, in Ethiopia, one in four people fail to meet their family planning needs [5]. Ethiopia faces polarization of the population between cities and local provinces, along with high total fertility rates and low family planning rates [6]. The difference in the total fertility rate between the Somali region, an area with high fertility, and Addis Ababa, an area with low fertility in 2016 was 5.4 [5].

The Federal Ministry of Health (FMOH) of Ethiopia announced "Ethiopia FP 2020" to address the high fertility rate, with the goal of reducing the fertility rate to 3.0 by 2020 [7]. In March 2019, SDG Performance Funds, a meeting of the Ethiopian government, $\mathrm{FMOH}$, and aid agencies in Ethiopia, discussed the budget allocation for family planning policies. The budget for Ethiopian family planning efforts has been a problem every year since the discussion started in 2012 [8]. The reason for this is that family planning resources were allocated in proportion to regions' populations. However, there was much disagreement as the project tried to curb an increase in the population. Accordingly, the meeting mentioned the importance of the basis for budget distribution by region and emphasized the need for research on family planning projects at the regional level $[9,10]$.

This study aims to identify the determinants of the use of modern family planning methods in three regions of Ethiopia.

\section{Materials And Methods}

\section{Study design}

This study used a community-based, cross-sectional mixed methods design. We selected the three largest from the nine regions in Ethiopia, being the Amhara, Oromia, and Somali regions. The Amhara region is located in the northwestern part of Ethiopia, while the Oromia region (which has the largest ethnolinguistic group in Ethiopia) is located in the central and western parts of the country [11], and the Somali region is located in the east and southeast.

The target group was married women and men living with a partner such as a husband, wife, or cohabitee in Amhara, Oromia, and Somali regions in Ethiopia.

\section{Sample size and data collection}

This study used two kinds of data: quantitative and qualitative. The sample size for the quantitative survey was determined using a double population proportion formula with the assumption of a $95 \%$ confidence level and $5 \%$ margin of error using G*Power software (version 3.0.10; Franz Faul, Kiel University, Kiel, Germany). The total sample size was estimated to be 2,494 married couples, including a $10 \%$ non-response rate. Respondents in the three regions were selected using the multistage cluster sampling method. First, we selected towns in each region - six towns in Amhara, four in Oromia, and four in Somali. The six towns of Amhara region included Gozamin, Bahirdar, Dessie, Debrebirhan, Debremarkos, and Dessie; Oromia's four towns included Jima, Adama, Chiro, and Assela; and Somali's four towns 
included Jijiga, Gode, Siti, and Kebridehar. Second, we randomly selected a rural area and an urban area in each target town. Third, for homogeneity, we randomly selected 20-40 married couples per Kebele (the smallest administrative unit) in the Amhara, Oromia, and Somali regions.

The questionnaire used in this study was adapted from the USAID Demographic and Health Survey 2016 in Ethiopia [5]. This structured questionnaire was first developed in English by reviewing diverse studies on each region. Thereafter, the questionnaire was translated into three languages: Aaharic, Affan Oromo, and Somali by experts who fluently speak both English and these local languages. The data collection was conducted through face-to-face interviews by enumerators from May 10 to May 31, 2017. We used the Open Data Kit (ODK) survey application on a tablet PC. We obtained data from 4,688 respondents living in Amhara, Oromia, and Somali regions, with a response rate of $93.9 \%$. Consequently, we excluded 571 respondents' answers due to missing or censored data. The final sample for this study consisted of 1,634 people from the Amhara region, 2,383 from the Oromia region, and 100 from the Somali region.

We conducted qualitative in-depth interviews with the key informants living in the target regions. The questionnaire was developed based on the "Qualitative Study on Family Planning" by UNFPA." Religious and community leaders helped us select the target respondents from whom we randomly selected 24 (8 per region), for key informant interviews.

\section{Variables}

The dependent variable was family planning practice experience. To measure this, we asked the respondents, "Have you (or your spouse) ever used any modern family planning methods (Pills, IUCD, Injectable, Implants, Emergency contraceptives, Foam, Condom, Vasectomy) to delay or stop a pregnancy?" A response of "Yes" was coded as "1" and other responses were coded as "0." This question was taken from the Demographic and Health Survey 2016 (DHS 2016) by USAID [5].

The independent variables were socio-demographic characteristics including region, age, sex, religion, occupation, and marital status. We also selected family planning variables including a family planning discussion with partner (spouse, friend, family, health professional, HEWs, religious leader, or community leader) and exposure to family planning messages.

The qualitative interview questionnaire had 9 themes and 29 questions. We used 7 themes: 1) Fertility Intention, 2) Knowledge, Perceptions \& Beliefs about Contraceptive Methods, 3) Experience of Contraceptive Use, 4) Reasons for discontinuing the use of the method, 5) Reasons for non-use of contraceptive, 6) Reasons for Unwanted Pregnancy and Seeking Induced Abortion, and 7) Future Intention on Contraceptive Use and Enabling Factors.

\section{Data analysis}

The quantitative data were subjected to binary logistic regression analysis to identify the determinants of modern family planning methods across the three regions. This analysis was performed using SPSS Statistics 24.0.

The qualitative data were recorded using a digital recorder and audio data were transcribed and then translated into English, saved as an MS Word file, and exported into Atlas-ti software for coding and categorization. Every item of the qualitative dataset was translated, and appropriate codes related to the evaluation objectives were assigned. Similar codes were grouped under the same category and a thematic content analysis was conducted. The themes were categorized into three types of reason: knowledge, interruption, and religion.

\section{Ethical approval}


Ethical approval was obtained from the Research Ethics Committee of the School of Public Health and the Institutional Review Board of the College of Health Science, Addis Ababa University (No. 032/17/SHP). Moreover, we obtained a support letter from the Federal Ministry of Health, regional health bureaus, and the study districts' health officers.

We obtained written informed consent from all participants for both the quantitative and qualitative surveys. We especially emphasized the respondents' right to refuse the interview. Couples were interviewed at the same time in separate places to avoid contaminating the data due to sensitive information being passed between spouses during the interviews.

\section{Results}

\section{Characteristics of the study respondents}

A total of 4,117 married men and women (aged 15-65) participated. Geographically, participants were representative of Amhara (1,634; 39.7\%), Oromia $(2,383 ; 57.9 \%)$, and Somali $(100 ; 2.4 \%)$. Table 1 depicts their characteristics by region. The mean age of the respondents was $32.2 \pm 8.8$ years and approximately half were male $(1,968 ; 47.8 \%)$. The identified religion of respondents were Muslim (1,942; 47.2\%) and Orthodox (1,836; 44.6\%). Most respondents were unemployed $(2,952 ; 71.7 \%)$.

(Table 1 Here)

\section{Quantitative analysis: Binary logistic regression}

Respondents in Oromia were 8.673 times more likely to use modern family planning methods compared to those from the Somali region (AOR=8.673, 95\% Cl: [5.160-14.581], p<.001). Moreover, those in Amhara were 5.183 times more likely to use modern family planning methods compared to those from the Somali region (AOR=5.183, 95\% Cl: [3.147-8.538], $p<.001$ ) (Table 2).

Based on gender, women were 1.764 times more likely to use modern family planning methods than men $(A O R=1.764$, 95\% Cl: [1.502-2.072], p<.001).

Respondents, whose occupation was housework, were 0.746 times less likely to use modern family planning methods than the no-work group ( $\mathrm{AOR}=.746,95 \% \mathrm{Cl}$ : [.566-.983, $p<.05]$, or conversely those who were unemployed were 1.34 times more likely to use modern family planning methods compared to houseworkers. Daily workers were 1.531 times more likely to use modern family planning methods than respondents who were unemployed ( $\mathrm{AOR}=1.531,95 \% \mathrm{Cl}$ : [.999-2.346], p<.001).

Married respondents were 2.277 times more likely to use modern family planning methods than respondents who lived with a partner but were not married $(A O R=2.277,95 \% \mathrm{Cl}$ : [1.593-3.255, p<.001]. Household monthly income was not a significant factor in modern family planning methods.

Respondents who discussed family planning with their spouse were 2.426 times more likely to use modern family planning methods than those who did not. Family planning discussions with HEWs (2.430 times) or a health professional (1.806 times) were significant factors in modern family planning methods.

Respondents who received family planning messages through the media were 1.210 times more likely to use modern family planning methods than those who did not (AOR=1.210, 95\% Cl: [1.043-1.404], $p<.05)$.

(Table 2 Here) 


\section{Qualitative analysis}

A total of 24 key informants participated in the study. Religious leaders, community leaders, HEWs, FP service providers, and heads of health centers assisted with the qualitative interviews of this study.

Some of the points that emerged from the qualitative interview respondents belonging to different religions are listed below. The results showed that family planning practices could be divided into three focal points: knowledge, interruption, and religion.

\section{Knowledge}

Some informants reported that they were aware of the importance of family planning for the health of both the mother and the newborn child. However, they said that opposition from their husband, spouse, or family stopped them from putting family planning strategies into practice.

"Child-spacing benefits both the mother's and child's health, but often husbands don't like their wives when they have few children, and as a result they often marry a second wife to get many children. But I believe that child-spacing is good; for example, children who are born spaced are physically stronger than those who are born in succession"[Somali, female, non-user]

On the other hand, many respondents did not use family planning because of incomplete or incorrect knowledge. Some respondents reported that family planning practices would cause a physical disease (such as skin disease, back pain, etc.), illness, or decreased sexual feeling.

"... I am male, but I hear people saying once a woman uses this family planning, she will never give birth again as her reproductive organ will be closed. In cases where she lacks adequate food, the pills cause damage to her belly, skin discoloration ("madiat") on her face, etc. These are some of the doubts or fears in our community." [Oromia, male, nonuser]

“... The drug results in weight gain and has a sensation of burning. It also makes the women aggressive and results in quarrels between husband and wife. It decreases love by reducing the sexual feelings of females; they also complain about pain during intercourse. I know many people who divorced because of this problem..." [Amhara, male, Orthodox religious leader]

\section{Interval in childbearing}

Some respondents stopped using family planning services because they faced problems like pain, disease, headaches, etc. The following quote is from an interview with a 30-year-old woman who used family planning for 7 years after the birth of her second child:

“...After the second child, she again used an injectable for some time but stopped using it because she thought that it caused aggression, headaches, an internal burning sensation, and her menses did not flow..." [Amhara, female, orthodox] There were no answers from the Oromia and Somali regions on this topic.

\section{Religion}

Most respondents who did not practice family planning for religious reasons were Muslims. This is because the Muslim community considers family planning practices such as condoms, implants, UIDs, etc., as taboo under Sharia law. 
Therefore, Muslims have a low rate of practicing family planning. The following interviews were conducted with Muslims in the Amhara, Oromo, and Somali regions:

"She aspires to have at least 10 children because she believes that having more children is more prestigious in the community and she will be respected more by her husband and his relatives. On the other hand, she believes that modern family planning methods are forbidden by Sharia and she has a plan to space her children using the calendar method and breast feeding, which are acceptable in Islam." [Somali, female, Muslim]

“....God said multiply and replenish the earth...children are gifts from God... when every child is born, he/she comes with his/her own fate/luck..." [Amhara, female, Orthodox]

"I believe that the only one who makes every decision of the household including family size and family planning use [is the man] since he is entitled under Sharia law." [Oromia, male, Muslim]

\section{Discussion}

In this study, the respondents' experience rate of modern family planning methods was $68.9 \%$ on average, with $75.7 \%$ in Amhara, followed by $65.0 \%$ in Oromia and $33.0 \%$ in Somali. The respondents discussed family planning with their spouses the most (87.5\%), followed by friends (29.9\%), health professionals (19.6\%), HEWs (8.5\%), religious leaders (2.4\%), family $(0.7 \%)$, and community leaders $(0.7 \%)$. This concurs with the extant DHS data which found that people discussed family planning mostly with their spouses (72.8\%) [5]. On the basis of region, family planning was discussed with spouses at the rate of $87.5 \%$ in Amhara, $88.9 \%$ in Oromia, and 54.0\% in Somali region. According to DHS 2016, the rate in Amhara was $75.8 \%, 11.7 \%$ lower than in this study, and the rate in Oromia was $72.8 \%$, or $16.1 \%$ lower than in this study. However, in Somali region (62.6\%), the rate was $8.6 \%$ higher than in this study.

The quantitative analysis showed that the rate of usage of modern family planning methods was significantly different for each region in Ethiopia. The use of modern family planning methods in Oromia was 8.673 times higher compared to the Somali region $(\mathrm{AOR}=8.673,95 \% \mathrm{Cl}$ : [5.160-14.583], $p<.001)$ and Amhara was 5.183 times higher compared to the Somali region (AOR=5.183, 95\% Cl: [3.147-8.538], $p<.001)$. These results were associated with Somali's total fertility rate of 7.2, twice that of Amhara (3.7) and more than 1.5 times that of Oromia (5.4) [11]. According to the quantitative and qualitative analyses, because $98.7 \%$ of the local residents in the Somali region followed Islam, and family planning (contraception) is prohibited under Sharia law, it is rarely used there. In particular, the use of condoms, implants, pills, and IUDs for family planning is prohibited, while only the calendar method and breastfeeding is permitted. In fact, the Quran clearly states, "Bring a lot of children for the prosperity of Islam" in the Quran, so there are limitations in implementing family planning policies for Muslims $[12,13]$.

According to a study by Tigabu (2018) on religious views on contraception in western Ethiopia, there is a belief that if a female Ethiopian Muslim dies with an implant, a female contraceptive device, in her body, her soul cannot go to heaven.

On the other hand, there were some opinions that ran contrary to our qualitative findings and the findings of previous studies. One Muslim woman responded that family planning was necessary because she perceived that her children were born healthy because of family planning, which controlled the age gap of her children. This demonstrates that, even though women themselves recognize the need for family planning, they fail to implement it for religious reasons. There is a $3.4 \%$ level of use of family planning in Somali region, where $98.7 \%$ of the population is Muslim, while $79.0 \%$ of women are aware of the importance of family planning [5]. There are, thus, many women who cannot practice family planning (contraception) for religious and doctrinal reasons, despite their wishes. Traditionally, Muslim husbands have all the decision-making power. A previous study on the use of condoms in Ethiopia found that, because family planning 
in Muslim families was decided by the husband, women faced many limitations in using/practicing modern family planning methods on their own $[15,16]$.

In this study, the proportion of women that decided on family planning after consultation with their husband was $54.0 \%$ in the Somali region, lower than in Amhara (87.5\%) and Oromia (88.9\%). Therefore, in the Somali region, it is important to educate religious leaders and heads of the family (e.g., husbands) about the importance of family planning (contraception) to increase the rate of family planning practice, thereby lowering the total fertility rate. In fact, after conducting educational sessions on family planning with Muslim religious leaders and men in three groups, it was found that their perceptions changed, which lowered the fertility rate and gestational disease rates $[17,18]$.

In Ethiopia, family planning projects such as education for health professionals, HEWs, and religious leaders, media education, and the distribution of brochures are carried out by various organizations including international organizations and NGOs, research institutes, and civic groups [8, 19-21]. Among them, the Small, Happy, and Prosperous family in Ethiopia, conducted by the Korea International Cooperation Agency, was identified as the most effective intervention for delivering family planning educational messages through the media [22, 23]. However, the Somali region has the lowest message exposure (radio: $4.8 \%$, TV: $6.6 \%$ ), so there are limitations in delivering family planning education content through the media [5]. Therefore, family planning education in the Somali region should involve 1) supplying equipment to send messages (to improve message exposure), and 2) providing direct education to religious leaders, husbands, and medical professionals. The details are as follows:

First, providing equipment (radios, TVs) to listen to messages will help improve message exposure in the Somali region and increase the effectiveness of education delivered through the media. In this study, the number of people with experiences of receiving family planning messages through the media (exposure experience) was 1.12 times higher $(A O R=1.120,95 \% \mathrm{Cl}:[1.043-1.404], p<.05)$ than the number of people with no experience of using family planning services. In particular, the transmission of messages has proved to be an effective and widely used intervention in previous studies $[23,24]$.

Second, education to increase awareness of family planning is necessary for family decision-makers and certain influential groups such as husbands, health professionals, and HEWs. In this study, the use of modern family planning methods depended on with whom these discussions were held. Those that discussed whether to use modern family planning methods with HEWs, which had the highest influence, were 2.430 times (AOR=2.430, 95\% Cl: [1.698-3.476], $p<.001)$ more likely to use the services compared to those that did not, and this result was statistically significant. This is because Ethiopian females were worried about getting scolded by their husbands. They therefore relied on, and consulted the most with, HEWs who were of the same gender and not a family member [25]. The second most influential group to discuss using modern family planning methods were spouses; the use of modern family planning methods after a discussion with a spouse increased by 2.426 times (AOR=2.426, 95\% Cl: [1.968-2.990], p<.0001) as compared to the absence of a discussion. The third most influential group was health professionals, where the use of family planning services was 1.448 times higher ( $\mathrm{AOR}=1.488,95 \% \mathrm{Cl}$ : [1.185-1.869], $p<.001)$ after a discussion with them.

On the other hand, discussions with friends, religious leaders, and community leaders were not significantly related to the use of modern family planning methods. Usage of these services increased when consulting with a decision-maker or influential health professional, but in some cases, false information prevented people from using them. According to the interviews in the qualitative survey, a male respondent heard from his neighbors that using modern family planning methods would block the female reproductive system and prevent his wife from future childbirth and he cited this as the reason for not using it. This shows that incorrect knowledge among major decision-makers such as husbands can act as a barrier to family planning. 
One limitation of this study were the discrepancies in the responses to the qualitative and quantitative surveys. The respondents of the qualitative survey were interviewed regardless of whether they had participated in the quantitative survey. To minimize errors in the quantitative and qualitative analytical results, there needs to be consistency in the respondents [26]. However, since we could not conduct corresponding qualitative surveys for all 4,117 respondents of the quantitative survey, the qualitative respondents were selected via conditional extraction. Moreover, the Somali region sample had only 98 respondents, because Muslim women avoided talking with outsiders and did not want to participate in the survey as it was about family planning. In future studies, it is necessary to minimize the errors in the analysis by equalizing the respondents in the qualitative and quantitative surveys.

Moreover, this study was conducted in three out of nine regions of Ethiopia: Amhara, Oromia, and Somali. In future studies, it is necessary to minimize errors by conducting surveys in all nine regions.

\section{Conclusion}

This study aimed to identify the determinants of the use of modern family planning methods in Ethiopia, and a mixed method approach using both quantitative and qualitative surveys was designed. This study was conducted in the three largest regions of Ethiopia: Amhara, Oromia, and Somali regions.

Compared to the Somali region, the use of modern family planning methods was significantly higher in the Amhara region (5.183 times higher) and the Oromia region (8.673 times higher). The reason, confirmed through the qualitative research, was that $98.7 \%$ of those in the Somali region were Muslims and there were limits in using modern family planning methods due to the absolute right of husbands to decide on family planning, the prevailing religious doctrine, and a lack of knowledge. In particular, although the results showed that people were aware of the importance of family planning, for religious reasons it was not possible to use it.

In addition, the use of modern family planning methods differed significantly depending on the person consulted. When participants consulted with their husband on whether to use modern family planning methods, usage increased by 2.426 times (a significant difference) compared to those that did not. When they consulted with a religious leader, usage increased by 1.806 times (not statistically significant). In addition, those that listened to a family planning message through the media had an increased usage of modern family planning methods by 1.210 times (a significant difference).

Thus, it is necessary for Ethiopia to establish a family strategy in consideration of the cultural and social characteristics of each region. In particular, the Somali region needs to educate husbands and religious leaders about the importance of family planning. Since there exists a shortage of media equipment, supplying media equipment or organizing a common radio/TV spot is necessary to enable their access to family planning messages.

\section{Abbreviations}

DHS: Demographic and Health Survey; FMOH: Federal Ministry of Health; FP: Family Planning; HEW: Health Extension Worker; IUCD: Intra Uterine Contraceptive Device; SDGs: Sustainable Development Goals; UNFPA: United Nations Population Fund

\section{Declarations}

\section{Ethics Approval and consent to participate}

Ethical approval was obtained from the Research Ethics Committee of the School of Public Health and the Institutional Review Board of the College of Health Science, Addis Ababa University (No. 032/17/SHP). 


\section{Consent for publication}

Not applicable

\section{Availability of data and materials}

The data used for the current study is available from the corresponding author on reasonable request.

\section{Competing Interests}

The authors declare no conflict of interest

\section{Funding}

This research was funded by Korea International Cooperation Agency (KOICA), grant number P2019-00160-1.

\section{Author Contributions}

Conceptualization, H.C.L. and E.W.N.; Data collection, E.G.K and Y.A.D.; Formal analysis, H.C.L. and E.G.K.; Funding acquisition Y.A.D.; Methodology, H.C.L. and E.W.N.; Writing - Original draft, H.C.L.; Writing - review \& editing E.G.K., Y.A.D. and E.W.N. All authors have read and agreed to the published version of manuscript.

\section{Acknowledgments}

We appreciate to respondent for participate for interview in three regions. and We also are grateful to our participants for taking time to discuss for the KOICA family planning project title "The National Campaign for Promoting Knowledge, Attitude and Behavioral Change in Population and Development in Ethiopia" from 2019-2023 (No. P2019-00160-1).

\section{References}

1. DESA, U.N. World Population Prospects 2019: Highlights. New York (US): United Nations Department for Economic and Social Affairs; 2019.

2. Family Planning 2020. About Us. http://www.familyplanning2020.org/microsite/about-us. Accessed 25 March 2020.

3. FP2020 Overview. http://www.familyplanning2020.org/sites/default/files/What-isFP2020_Factsheet_updated_v1.pdf. Published 2020. Accessed 27 March 2020.

4. Contraceptives and condoms for family planning and STI/HIV. https://www.unfpa.org/sites/default/files/pubpdf/UNFPA_External_Procurement_Support_Report.pdf. Published 2014. Accessed 28 March 2020.

5. ICF International, Central Statistical Agency. Ethiopia Demographic and Health Survey, 2016. https://dhsprogram.com/pubs/pdf/FR328/FR328.pdf. Published 2017. Accessed 23 March 2020.

6. Ethiopia National Human Development Report 2018: Industrialization with a Human face. http://hdr.undp.org/sites/default/files/ethiopia_national_human_development_report_2018.pdf. Published 2018. Accessed 5 April 2020.

7. Family Planning 2020 Commitment.

8. https://www.familyplanning2020.org/sites/default/files/Govt.-of-Ethiopia-FP2020-Commitment-2018-Update.pdf. Published 2017. Accessed 10 April 2020.

9. Federal Democratic Republic of Ethiopia, Ministry of Health. National Guideline for Family Planning Services in Ethiopia. https://stage.prb.org/wp-content/uploads/2018/05/National-Guideline-for-Family-Planning-Services-in- 
Ethiopia-2011.pdf. Published 2001. Accessed 10 April 2020.

10. Expenditures on Family Planning in FP2020 Focus Countries in 2015.

http://www.track20.org/download/pdf/Expenditures_Assessment_12.5.17.pdf. Published 2017. Accessed 15 April 2020.

11. Factsheet Family Planning 2020: New and Renewed Commitments.

12. https://www.familyplanning2020.org/sites/default/files/FP2020_New_Commitments_7.13.2016-FINAL.pdf. Published 2016. Accessed 20 April 2020.

13. Encyclopedia Britannica. Oromo people. https://www.brcom/topic/Oromo. Accessed 25 April 2020.

14. Sundararajan $\mathrm{R}$, et al. How gender and religion impact uptake of family planning: results from a qualitative study in Northwestern Tanzania. BMC Women's Health. 2019;19(1): 99. https://doi.org/10.1186/s12905-019-0802-6

15. The Quran Commentaries for 4.1. Quranx Website. https://quranx.com/Tafsirs/4.1. Published. Accessed 25 April 2020.

16. Tigabu S, et al. Socioeconomic and religious differentials in contraceptive uptake in western Ethiopia: A mixedmethods phenomenological study. BMC Women's Health. 2018;18(1): 85. https://doi.org/10.1186/s12905-0180580-6

17. Programme of Action of the International Conference on Population and Development. https://www.unfpa.org/sites/default/files/event-pdf/PoA_en.pdf. Published 2004. Accessed 25 April 2020.

18. Kasa AS, Tarekegn M, Embiale N. Knowledge, attitude and practice towards family planning among reproductive age women in a resource-limited setting of Northwest Ethiopia. BMC Res Notes. 2018;11(1): 1-6. https://doi.org/10.1186/s13104-018-3689-7

19. Sueyoshi S, Al-Khozahe HO, Ohtsuka R. Effects of reproduction norms on contraception practice among Muslim women in Amman, Jordan. Eur J Contracept Reprod Health Care. 2006;11(2): 138-145. http://doi.org/10.1080/13625180500539430

20. Sharma V, et al. Sociodemographic determinants and knowledge, attitude, practice: Survey of family planning. J Family Med Prim Care. 2012;1(1): 43. http://doi.org/10.4103/2249-4863.94451

21. WHO. UNFPA. Family Planning for Health and Development: Action for Change. https://www.unfpa.org/sites/default/files/pub-pdf/KampalaReportlBP.pdf. Published 2006. Accessed 25 April 2020.

22. Federal Democratic Republic of Ethiopia Ministry of Health. Costed Implementation Plan for Family Planning in Ethiopia 2015/16-2020. http://www.healthpolicyplus.com/ns/pubs/2021-2030_EthiopiaCIPNov.pdf. Published 2016. Accessed 30 April 2020.

23. Alemayehu $\mathrm{M}$, et al. Family planning use and associated factors among pastoralist community of Afar region, eastern Ethiopia. BMC Women's Health. 2016;16(1): 39. https://doi.org/10.1186/s12905-016-0321-7

24. Paek HJ, et al. Rationale, design, and characteristics of the multimedia family planning campaign for a small, happy, and prosperous family in Ethiopia (SHaPE). BMC Pub Health. 2018;18(1): 861. https://doi.org/10.1186/s12889-018-5799-5

25. Etana D, Gurmu E. The effect of mass media on women's reproductive health behavior in Ethiopia. East Afr Soc Sci Res Rev. 2018;34(2): 37-58. https://doi.org/10.1353/eas.2018.0013

26. Ali E. Political activism and social media responsibility in Ethiopia: The case of Facebook \& Twitter [PhD Thesis]. Ethiopia: Addis Ababa University; 2019. http://localhost:80/xmlui/handle/123456789/18855. Accessed 25 April 2020.

27. Olson DJ, Piller A. Ethiopia: An emerging family planning success story. Stud Fam Plann. 2013;44(4): 445-459. https://doi.org/10.1111/j.1728-4465.2013.00369.x

Page $11 / 18$ 
28. Bulsara C. Using a mixed methods approach to enhance and validate your research. Brightwater Group Research Centre. 2015; 1-82.

\section{Tables}

Table 1 Respondent characteristics by region. 


\begin{tabular}{|c|c|c|c|c|c|c|c|c|}
\hline Variables & $\begin{array}{l}\text { Total } \\
(n=4,117)\end{array}$ & $\begin{array}{l}\text { Amhara } \\
\text { Population } \\
(N=20,401,000)\end{array}$ & $\begin{array}{l}\text { Oromia } \\
\text { Population } \\
(N=33,692,000)\end{array}$ & $\begin{array}{l}\text { Somali } \\
\text { Population } \\
(N=6,453,000)\end{array}$ & & & & \\
\hline $\begin{array}{l}\text { Respondents } \\
(n=1,634, \\
0.008 \%)\end{array}$ & $\begin{array}{l}\text { Respondents } \\
(n=2,383, \\
0.007 \%)\end{array}$ & $\begin{array}{l}\text { Respondents } \\
(n=100 \\
0.002 \%)\end{array}$ & & & & & & \\
\hline$N$ & $\%$ & $\mathrm{~N}$ & $\%$ & $N$ & $\%$ & $\mathrm{~N}$ & $\%$ & \\
\hline \multicolumn{9}{|l|}{$\begin{array}{l}\text { FP } \\
\text { experience }\end{array}$} \\
\hline No & 1,281 & 31.1 & 381 & 23.3 & 833 & 35.0 & 67 & 67.0 \\
\hline Yes & 2,836 & 68.9 & 1,253 & 76.7 & 1,550 & 65.0 & 33 & 33.0 \\
\hline \multicolumn{9}{|l|}{ Age } \\
\hline $15-19$ & 129 & 3.1 & 37 & 2.3 & 85 & 3.6 & 7 & 7.0 \\
\hline $20-29$ & 1,700 & 41.3 & 613 & 37.5 & 1,058 & 44.4 & 29 & 29.0 \\
\hline 30-39 & 1,405 & 34.1 & 558 & 34.1 & 804 & 33.7 & 43 & 43.0 \\
\hline $40-49$ & 709 & 17.2 & 343 & 21.0 & 349 & 14.6 & 17 & 17.0 \\
\hline $50-60$ & 138 & 3.4 & 65 & 4.0 & 69 & 2.9 & 4 & 4.0 \\
\hline $60-65$ & 36 & 0.9 & 18 & 1.1 & 18 & 0.8 & 0 & 0 \\
\hline \multicolumn{9}{|l|}{ Sex } \\
\hline Male & 1,968 & 47.8 & 805 & 49.3 & 1,129 & 47.4 & 34 & 34.0 \\
\hline Female & 2,149 & 52.2 & 829 & 50.7 & 1,254 & 52.6 & 66 & 66.0 \\
\hline \multicolumn{9}{|l|}{ Religion } \\
\hline Protestant & 132 & 7.9 & 50 & 3.1 & 274 & 11.5 & 0 & 0 \\
\hline Orthodox & 1,836 & 44.6 & 1,100 & 67.3 & 728 & 30.5 & 8 & 8.0 \\
\hline Muslim & 1,942 & 47.2 & 481 & 29.4 & 1,369 & 57.4 & 92 & 92.0 \\
\hline Catholic & 15 & 0.4 & 3 & 0.2 & 12 & 0.5 & 0 & 0 \\
\hline \multicolumn{9}{|l|}{ Occupation } \\
\hline Unemployed & 2,952 & 71.7 & 1,174 & 71.8 & 138 & 72.9 & 40 & 40.0 \\
\hline Farmer & 573 & 13.9 & 317 & 19.4 & 255 & 10.7 & 1 & 1.0 \\
\hline Trader & 89 & 2.2 & 27 & 1.7 & 56 & 2.3 & 6 & 6.0 \\
\hline Houseworker & 360 & 8.7 & 58 & 3.5 & 262 & 11.0 & 40 & 40.0 \\
\hline Daily worker & 143 & 3.5 & 58 & 3.5 & 72 & 3.0 & 13 & 13.0 \\
\hline \multicolumn{9}{|l|}{$\begin{array}{l}\text { Marital } \\
\text { status }\end{array}$} \\
\hline Married & 3,968 & 96.4 & 1,582 & 96.8 & 2,287 & 96.0 & 99 & 99.0 \\
\hline
\end{tabular}




\begin{tabular}{|c|c|c|c|c|c|c|c|c|}
\hline Cohabiting & 149 & 3.6 & 52 & 3.2 & 96 & 4.0 & 1 & 1 \\
\hline \multicolumn{9}{|l|}{$\begin{array}{l}\text { Household } \\
\text { monthly } \\
\text { income }\end{array}$} \\
\hline$\leq 500 \mathrm{ETB}$ & 120 & 2.9 & 50 & 3.1 & 70 & 2.9 & 0 & 2.9 \\
\hline $\begin{array}{l}501-1,000 \\
\text { ETB }\end{array}$ & 638 & 15.5 & 296 & 18.1 & 341 & 14.3 & 1 & 15.5 \\
\hline $\begin{array}{l}1,001-1,500 \\
\text { ETB }\end{array}$ & 616 & 15.0 & 279 & 17.1 & 331 & 13.9 & 6 & 15.0 \\
\hline $\begin{array}{l}1,501-2,000 \\
\text { ETB }\end{array}$ & 142 & 10.0 & 162 & 9.9 & 249 & 10.4 & 1 & 10.0 \\
\hline $\begin{array}{l}2,001-2,500 \\
\text { ETB }\end{array}$ & 569 & 13.8 & 197 & 12.1 & 358 & 15.0 & 14 & 13.8 \\
\hline $\begin{array}{l}2,501-3,000 \\
\text { ETB }\end{array}$ & 324 & 7.9 & 136 & 8.3 & 179 & 7.5 & 9 & 7.9 \\
\hline$\geq 3000$ ETB & 1,438 & 34.9 & 514 & 31.5 & 855 & 35.9 & 69 & 34.9 \\
\hline \multicolumn{9}{|l|}{$\begin{array}{l}\text { FP } \\
\text { discussion } \\
\text { with spouse }\end{array}$} \\
\hline No & 515 & 12.5 & 205 & 12.5 & 264 & 11.1 & 46 & 46.0 \\
\hline Yes & 3,602 & 87.5 & 1,429 & 87.5 & 2,119 & 88.9 & 54 & 54.0 \\
\hline \multicolumn{9}{|l|}{$\begin{array}{l}\text { FP } \\
\text { discussion } \\
\text { with friend }\end{array}$} \\
\hline No & 2,886 & 70.1 & 1,030 & 63.0 & 1,784 & 74.9 & 72 & 72.0 \\
\hline Yes & 1,231 & 29.9 & 604 & 37.0 & 599 & 25.1 & 28 & 28.0 \\
\hline \multicolumn{9}{|l|}{$\begin{array}{l}\text { FP } \\
\text { discussion } \\
\text { with family }\end{array}$} \\
\hline No & 4,012 & 97.4 & 1,559 & 95.4 & 2,356 & 98.9 & 97 & 97.0 \\
\hline Yes & 105 & 2.6 & 75 & 4.6 & 27 & 1.1 & 3 & 3.0 \\
\hline \multicolumn{9}{|l|}{$\begin{array}{l}\text { FP } \\
\text { discussion } \\
\text { with health } \\
\text { professional }\end{array}$} \\
\hline No & 3,312 & 80.4 & 1,349 & 82.6 & 1,901 & 79.8 & 62 & 62.0 \\
\hline Yes & 805 & 19.6 & 285 & 17.4 & 482 & 20.2 & 38 & 38.0 \\
\hline \multicolumn{9}{|l|}{$\begin{array}{l}\text { FP } \\
\text { discussion } \\
\text { with HEW }\end{array}$} \\
\hline No & 3,767 & 91.5 & 1,521 & 93.1 & 2,176 & 91.3 & 70 & 70.0 \\
\hline Yes & 350 & 8.5 & 113 & 6.9 & 207 & 8.7 & 30 & 30.0 \\
\hline
\end{tabular}




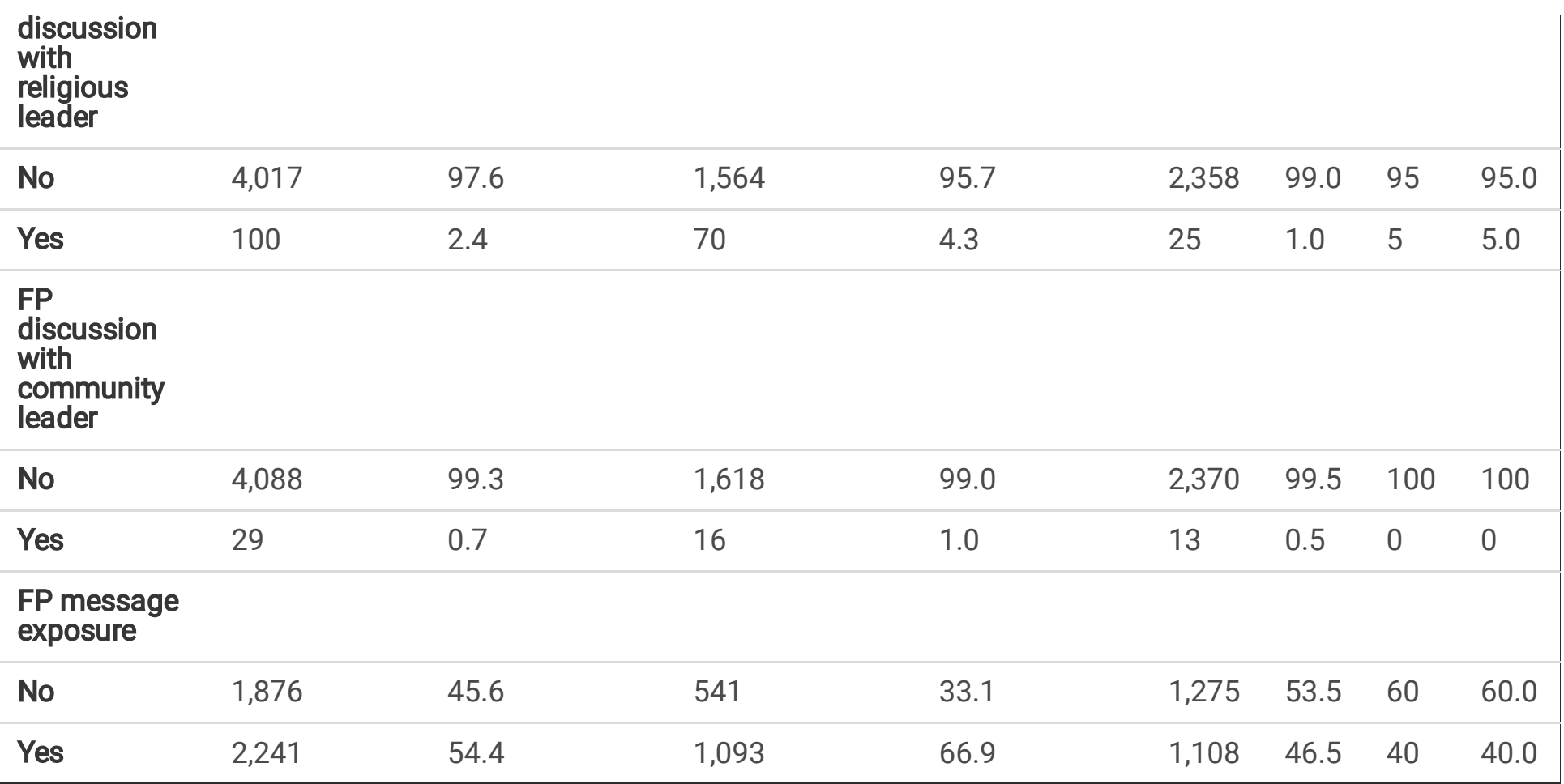

${ }^{1} \mathrm{FP}=$ Family planning; HEW $=$ Health Extension Worker

Table 2 Binary logistic regression analysis of FP experiences in Amhara, Oromia, and Somali regions. 


\begin{tabular}{|c|c|c|c|c|}
\hline Variables & $\begin{array}{l}\text { FP experience } \\
(\%)\end{array}$ & $\begin{array}{l}\mathrm{COR}(95 \% \\
\mathrm{Cl})\end{array}$ & AOR $(95 \% \mathrm{Cl})$ & \\
\hline No & Yes & & & \\
\hline \multicolumn{5}{|l|}{ Regions } \\
\hline Somali & $67(67.0)$ & $33(33.3)$ & 1 & 1 \\
\hline Oromia & $833(35.0)$ & $1,550(65.0)$ & $\underset{* \star \star}{6.677}[4.333-10.288]$ & $\underset{\star \star \star \star}{8.673}[5.160-14.581]$ \\
\hline Amhara & $381(23.3)$ & $1,253(76.7)$ & $\underset{\star \star \star}{3.778}[2.469-5.780]$ & $\underset{\star \star \star \star}{5.183}[3.147-8.538]$ \\
\hline \multicolumn{5}{|l|}{ Age } \\
\hline $15-19$ & $82(63.6)$ & $47(36.4)$ & 1 & 1 \\
\hline $20-29$ & $567(33.4)$ & $1,133(66.6)$ & $3.486[2.402-5.060]$ & $3.481[2.338-5.182]$ \\
\hline $30-39$ & $314(22.3)$ & $1,091(77.7)$ & $\underset{* \star 0 *}{6.062[4.146-8.864]}$ & 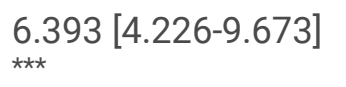 \\
\hline $40-49$ & $226(31.9)$ & $483(68.1)$ & $3.729[2.520-5.517]$ & $4.013[2.594-6.206]$ \\
\hline $50-60$ & $71(51.4)$ & $67(48.6)$ & $1.646\left[1.009-2.687^{\star}\right]$ & $2.053[1.190-3.542]$ \\
\hline $60-65$ & $21(58.3)$ & $15(41.7)$ & $1.246[.587-2.647]$ & $1.748[.772-3.961]$ \\
\hline \multicolumn{5}{|l|}{ Sex } \\
\hline Male & $689(35.0)$ & $1,279(65.0)$ & 1 & 1 \\
\hline Female & $592(27.5)$ & $1,557(72.5)$ & $1.417[1.241-1.617]$ & $1.764[1.502-2.072]$ \\
\hline \multicolumn{5}{|l|}{ Religion } \\
\hline Protestant & $98(30.2)$ & $226(69.8)$ & 1 & 1 \\
\hline Orthodox & $460(25.1)$ & $1,376(74.9)$ & 1.735 [.479-6.283] & 1.044 [.267-4.083] \\
\hline Muslim & $720(37.1)$ & $1,222(62.9)$ & $.736[.571-.949]^{*}$ & $.836[.636-1.100]$ \\
\hline Catholic & $3(20.0)$ & $12(80.0)$ & $1.297[1.001-1.681]^{*}$ & 1.164 [.875-1.549] \\
\hline \multicolumn{5}{|l|}{ Occupation } \\
\hline Unemployed & $903(30.6)$ & $2,049(69.4)$ & 1 & 1 \\
\hline Farmer & 188(32.8) & $385(67.2)$ & $.792[.540-1.161]$ & $.965[.769-1.210]$ \\
\hline Trader & $22(24.7)$ & $67(75.3)$ & .715 [.473-1.080] & $1.677[.985-2.854]$ \\
\hline Houseworker & $131(36.4)$ & $229(63.6)$ & $1.063[.578-1.956]$ & $.746[.566-.983]^{*}$ \\
\hline Daily worker & $37(25.9)$ & 106(74.1) & $.610[.396-.939]^{*}$ & $1.531[.999-2.346]^{\star \star \star}$ \\
\hline
\end{tabular}




\begin{tabular}{|c|c|c|c|c|}
\hline Cohabiting & 74(49.7) & $75(50.3)$ & 1 & 1 \\
\hline Married & $1,207(30.4)$ & $2,761(69.6)$ & $2.287[.319-.615]^{\star \star \star}$ & $2.277[1.593-3.255]$ \\
\hline
\end{tabular}

Household monthly income

\begin{tabular}{lllll}
$\mathbf{\leq} \mathbf{5 0 0}$ ETB & $36(30.0)$ & $84(70.0)$ & 1 & 1 \\
\hline $\mathbf{5 0 1 - 1 , 0 0 0 ~ E T B ~}$ & $220(34.5)$ & $418(65.5)$ & $.814[.533-1.243]$ & $.829[.528-1.300]$ \\
\hline $\mathbf{1 , 0 0 1 - 1 , 5 0 0 ~ E T B ~}$ & $222(36.0)$ & $394(64.0)$ & $.761[.498-1.162]$ & $.746[.475-1.173]$ \\
\hline $\mathbf{1 , 5 0 1 - 2 , 0 0 0 ~ E T B ~}$ & $130(31.6)$ & $282(68.4)$ & $.930[.597-1.447]$ & $.901[.562-1.446]$ \\
\hline $\mathbf{2 , 0 0 1 - 2 , 5 0 0 ~ E T B ~}$ & $176(30.9)$ & $393(69.1)$ & $.957[.623-1.470]$ & $1.028[.649-1.628]$ \\
\hline $\mathbf{2 , 5 0 1 - 3 , 0 0 0}$ ETB & $103(31.8)$ & $221(68.2)$ & $.920[.583-1.450]$ & $.951[.583-1.551]$ \\
\hline $\mathbf{2} \mathbf{3 0 0 0}$ ETB & $394(27.4)$ & $1,044(72.6)$ & $.1 .136[.756-1.706]$ & $1.240[.800-1.922]$ \\
\hline FP discussion with spouse & & & & \\
\hline No & $225(49.5)$ & $260(50.5)$ & 1 & 1 \\
\hline Yes & $1,026(28.5)$ & $2,576(71.5)$ & $2.462[2.042-2.970]$ & $2.426[1.968-2.990]$ \\
& & & &
\end{tabular}

FP discussion with friend

\begin{tabular}{|lllll}
\hline No & $976(33.8)$ & $1,910(66.2)$ & 1 & 1 \\
\hline Yes & $305(24.8)$ & $926(75.2)$ & $\underset{* \star *}{*}$ 1.551 [1.334-1.804] & $.991[.830-1.182]$
\end{tabular}

FP discussion with family

\begin{tabular}{lllll} 
No & $1,262(31.5)$ & $2,750(68.5)$ & 1 & 1 \\
\hline Yes & $19(18.1)$ & $86(81.9)$ & $\underset{* *}{2.077[1.258-3.429]}$ & $.902[.515-1.582]$
\end{tabular}

FP discussion with health professional

\begin{tabular}{lllll} 
No & $1,114(33.6)$ & $2,198(66.4)$ & 1 & 1 \\
\hline Yes & $167(20.7)$ & $638(79.3)$ & $1.936[1.609-2.330]$ & $\begin{array}{c}1.488[1.185-1.869] \\
\star \star \star\end{array}$
\end{tabular}

\section{FP discussion with HEW}

\begin{tabular}{|c|c|c|c|c|}
\hline No & $1,224(32.5)$ & $2,543(67.5)$ & 1 & 1 \\
\hline Yes & $57(16.3)$ & 293(83.7) & $\underset{\star \star \star \star}{2.474}[1.848-3.313]$ & $\underset{* \star \star \star}{2.430}[1.698-3.476]$ \\
\hline \multicolumn{5}{|c|}{ FP discussion with religious leader } \\
\hline No & $1,268(31.6)$ & $2,749(68.4)$ & 1 & 1 \\
\hline Yes & $13(13.0)$ & $87(87.0)$ & $3.087[1.717-5.550]$ & $1.806[.922-3.539]$ \\
\hline
\end{tabular}


FP discussion with community leader

\begin{tabular}{|c|c|c|c|c|}
\hline No & & & 1 & 1 \\
\hline Yes & & & 1.187 [.524-2.687] & $.427[.159-1.143]$ \\
\hline \multicolumn{5}{|c|}{$\begin{array}{l}\text { FP message exposure through } \\
\text { media }\end{array}$} \\
\hline No & $641(34.2)$ & $1,235(65.8)$ & 1 & 1 \\
\hline Yes & $640(28.6)$ & $1,601(71.4)$ & ${ }_{\star \star \star \star}^{1.298}[1.137-1.482]$ & $1.210[1.043-1.404]$ * \\
\hline Hosmer \& Lemeshow & & & & $P=.803$ \\
\hline Negelkerke $\mathrm{R}^{2}$ & & & & .176 \\
\hline
\end{tabular}

$\star P<.05, * \star P<.01, * \star \star * P<.001$ 